\title{
INTRODUCTION
}

For many years it was believed that the collection of dusts originating from ferro-alloy operations was hardly possible, due to the extreme fineness of the dust and its particular metallurgical and physical properties. It was also thought that too little experience was available with manufacturers of gas cleaning equipment and this, it must be admitted, is largely due to the fact that until a few years ago no great pressure was exercised on the ferro-alloy industry in general to clean up their houses, as a result of which gas cleaning plant designers would perhaps have put greater emphasis on the development of suitable equipment for this purpose. This situation, however, seems to change rather rapidly in the light of world-wide pressure exercised on all industries which create air pollution problems, the ferro-alloy industry included. Substantial progress has been made in this field and it can today be said that in a great number of countries the problems of cleaning the exhaust gases from ferro-alloy operations have been suitably approached and a good deal of progress has been made. Notably, in the U.S.A. and Japan, where a substantial number of ferro-alloy producers are operating, developments have taken place which have opened the eyes of engineers throughout the world, but from other countries as well news has been received which indicates that in the not too distant future air pollution problems in the ferro-alloy industry will be solved and standards of clean air will be achieved which will meet the requirements of modern control legislation.

During the recent Disseldorf Air Pollution Conference a number of papers were presented which deserve recognition and acknowledgement. LARS LINDAU of the Swedish Environment Protection Board reported about progress made in Sweden, where some 30 furnaces with a total power input of just over $300 \mathrm{MW}$ were in operation in 1971. Of these about 10 units are equipped with gas cleaning devices, and about 5 will be shut down shortly. In Sweden experiments were carried out not only with bag type 
collectors but also with electro-filters and in one instance with a gravel bed filter. For the latter, a cleangas burden of $400 \mathrm{mg} / \mathrm{Nm}^{3}$ was specified, but at present the plant only reaches about $1000 \mathrm{mg} / \mathrm{Nm}^{3}$. Improvements are expected. The electrofilter installation proved to be not too successful as it had to be reconstructed fully in stainless steel and needed ammonia injection to achieve acceptable results. Bagfilters were installed on $\mathrm{Fe}-\mathrm{Si}$ and $\mathrm{Si}-m e t a l$ producing furnaces and most of these plants are now in operation for periods of less than two years, so that no clear picture on baglife and operational performance can as yet be obtained.

STANISLAW HAMERLAK of Poland reported about a gascleaning plant installed on two $20 \mathrm{MVA} \mathrm{Fe-Si} \mathrm{furnaces} \mathrm{which} \mathrm{went} \mathrm{into} \mathrm{operation} \mathrm{in} 1971$. Extensive research was carried out prior to the construction of the plant, giving special consideration to the characteristics of the fumes originating from the smelter operations, such as extreme fineness of the dust particles, low bulk density and extremely high electric resistivity of the dust. This plant used Polyester filter bags at a specific load value of $40 \mathrm{~m}^{3} / \mathrm{m}^{2} \mathrm{~h}$ and at 150 to 200 WG pressure drop across the fabric. Cleangas burdens were in the region of 40 to $70 \mathrm{mg} / \mathrm{Nm}^{3}$, at a rawgas dust burden of 2 to $3,5 \mathrm{~g} / \mathrm{Nm}^{3}$. An interesting feature in this instance is the gas cooling process used, i.e. adiabatic cooling by water injection into the hot furnace off-gas is applied, whereby the water is introduced as a fog. The system enables gas cooling from 240 to $400^{\circ} \mathrm{C}$ at the furnace to the permissible temperature for Polyester of 130 to $150^{\circ} \mathrm{C}$ at filter inlet. - The recovered dust is mixed with 5 - 10\% lime milk and then pumped to slimes dams where, after air drying, it settles to a hard, solid mass. Between 7000 and 8000 t are recovered per year.

E. PIEPER and K. VAY tabled summarised results on closed and open ferroalloy furnaces, from which it can be taken that $\mathrm{FeSi}$ and $\mathrm{FeCr}$ were produced in open furnaces throughout, whilst FeMn and FeSiMn processes use closed furnaces only. For the latter, high pressure venturi plants proved to be very successful, whereas for open or semi-closed furnaces 
it would appear that fabric type collectors produced the best results. Pressure drops experienced with dry plants were between 150 to $220 \mathrm{~mm}$ WG and cleangas dust burdens in all instances were less than $50 \mathrm{mg} / \mathrm{Nm}^{3}$.

\section{THE DUST}

In almost all ferro-alloy smelter applications it has been found that the dusts are extremely fine, with the multitude of the grain being in the below 1 micron range, and frequently with some 40 to $50 \%$ being even smaller than 0,5 micron. The specific weight of the dust is in the 2,0 to $2,4 \mathrm{~g} / \mathrm{m}^{3}$ range, but when aerated the bulk density of the dust is often less than 0,2 to $0,3 \mathrm{t} / \mathrm{m}^{3}$ which in itself poses substantial problems when disposing of the dust.

Certain ferro-alloy dusts, and specifically FeSi dusts, due to their high $\mathrm{SiO}_{2}$ content, have extremely high electric resistivities, which create special problems for dust release from the filter fabrics.

Experiments carried out in Japan for instance show that static D.C. voltages of up to $50000 \mathrm{~V}$ can occur in baghouses, for which special measures must be taken to release the dust from the filter fabric efficiently since otherwise a steadily increasing blinding of the fabric would occur, which could lead to subsequent bag failure by fabric rupture.

Means to lead off the static charge from the fabric include woven-in metal fibres, anti-static cages onto which the bags are mounted, or socalled flo-bak rings which are inserted into the filter bags. Again, Japanese sources quote that the use of flo-bak rings for instance results in the reduction of static charges to some 2000 Volts, a potential at which it is seemingly possible to operate a bagfilter for years at moderate pressure drops of 150 to $250 \mathrm{~mm}$ WG across the fabric.

\section{FILTER FABRICS}

It can be generally said that for ferro-alloy applications only two fabrics have been used in baghouses successfully and over several years, namely glassfibre and polyester, both woven. Recently it appears that 
Nomex fabrics have been used with some success, according to information received from U.S.A.

The main difference in the use of the various types of fabrics lies in the temperature range, within which these fabrics can be applied. Glassfibre has the toughest temperature resistance of all fabrics and can be operated safely in the $260^{\circ} \mathrm{C}$ range, with peaks up to $280^{\circ} \mathrm{C}$. (The writer witnessed a plant in Japan which at the time operated at $330^{\circ} \mathrm{C}$ without any apparent detriment to the fabric).

Polyester fabrics in turn have a lower temperature limit, i.e. continuous operating temperatures should not exceed 130 to $140^{\circ} \mathrm{C}$, with peaks up to $150^{\circ} \mathrm{C}$. As a comparison Nomex fabrics can stand gas temperatures of up to 200 to $220^{\circ} \mathrm{C}$. but too little operational experience on ferroalloy applications is available to comment further on the subject.

Although non-woven filter fabrics have become a widely used filtration media in general gas cleaning procedures, it would appear that in ferroalloy applications woven fabrics are still being used throughout. This is perhaps due to the fact that on account of the vast gas volumes emitted from ferro-alloy smelting applications, only large size baghouses can be used economically involving filter bags of extreme lengths which, if they were made of non-woven fabrics, would stretch too much under the influence of heat, gas pressure and cleaning operations. To the best of our knowledge it has, as yet, not been possible to produce glassfibre fabrics of the non-woven type.

Without going into too much detail regarding weaving techniques and fibres used, it can be said that only very high quality fabrics can be used for ferro-alloy applications, in view of the arduous operating conditions and the extremely fine grain distribution of the dust. Bursting strengths have to be high, permeabilities on account of the above are low (in the region of 8,0 to $30 \mathrm{~m}^{3} / \mathrm{m}^{2} \mathrm{~min}$ ) and as a result, unusually high pressure drops across the bags are experienced which can go up as high as $250 \mathrm{~mm}$ WG at operating conditions. 
Glassfibre fabrics are today treated by silicon/graphite application in order to protect the otherwise brittle glassfibre against flex fatigue. Japanese manufacturers apply graphite treatment to polyester fabrics as well, for better protection of the material.

As to baglife of for instance glassfibre fabrics, conflicting reports are received from various users throughout the world. However, in conclusion it can be said that if this material is used in the correct way, operational periods of two years and more can be obtained without difficulty. In fact, reports from some Japanese plants indicate that bags are still in a satisfactory condition after 3 years of continuous operation.

Foremost requirement for flassfibre bags is that they are not mechanically shaken for cleaning but that the deflation process is used which affords a gentle treatment of the bags during cleaning operations. A close watch must be kept on the gas temperature since under extreme and continuous surge conditions, fabric destruction could take place, which would reduce baglife considerably. - Polyester is equally sensitive as regards gas temperature but can be mechanically cleaned although baghouse manufacturers prefer the deflation process being applied to this fabric grade as well.

In most known installations, bags of approximately $300 \mathrm{~mm}$ diameter are used, with bag lengths being on average of 8 to 10 metres. Japanese manufacturers for some years have been using bags with a length of up to 13 metres and results so far obtained seem to be perfectly satisfactory. Obviously, the longer the individual bag, the lesser is the number of total bags installed and hence the lower is the cost of the baghouse installation.

There does not appear to be any substantial price difference between glassfibre and polyester fabrics and hence the choice whether to use either of the two depends on the temperature of the gases introduced to the baghouses respectively on the economics of the processes used for 
the cooling of the gases after they have left the furnaces.

\section{GAS COOLING}

Whilst in the past plant operators have experimented with a number of cooling processes on ferro-alloy furnaces, there seems to be a tendency today to apply radiation cooling in preference to any other cooling method. Generally, gas cleaning plants are often installed a certain distance away from the smelter houses and in many instances no extra effort has to be made for radiation cooling as the length of gas duct involved affords the required temperature reduction from furnace exit to baghouse entry. This is particularly so when glassfibre bags are used, as with furnace exit temperatures of say 300 to $350^{\circ} \mathrm{C}$ and permissible baghouse inlet temperatures of $260^{\circ} \mathrm{C}$, temperature reductions of between 60 to $100^{\circ} \mathrm{C}$ can easily be achieved by straight radiation. Where space limitations exist, U-tube coolers are applied which equally use the radiation technique, but require substantially less ground space.

The gas cooling process becomes more involved when low temperature baghouses are used, employing Polyester filter bags. The required temperature reduction is then substantially greater and this in turn necessitates bigger heat exchange areas. Dilution by air is another possibility, but the greater gas volumes resulting therefrom work against an economical solution.

It is interesting to note that in Japan almost all ferro-alloy gas cleaning plants apply the high temperature technique, i.e. glassfibre bags are used and gas temperatures are seldom less than $200^{\circ} \mathrm{C}$ at baghouse inlet. The newest plant for a FeSi smelter presently constructed in South Africa will equally apply glassfibre filter bags and design gas temperatures in this instance will be in the $200^{\circ} \mathrm{C}$ range, with the possibility of going up to $260^{\circ} \mathrm{C}$, should the smelter process be changed at a later stage.

\section{BAGHOUSE DESIGN}

Both the pressure as well as the suction type baghouse have been success- 
fully used in the ferro-alloys industry, with an apparent preference having been given to the pressure type. The main reason for this preferance is clear; the baghouse acts as gas discharge stack so that no extra costs have to be borne for separate stacks following the main fans, which would be the case if suction type units were used. In view of the very fine grain distribution and the relatively low abrasive characteristics of ferro-alloy dust in general, it is quite feasible to install the main fan on the upstream side of the baghouse, whereby the main fan would at this point act as a final booster to discharge the gases through the baghouse system to atmosphere. For such arrangement it is obviously necessary to give special consideration to the fan design, a matter which will be dealt with later on.

Another advantage of the pressure type baghouse is that it does not need to be built as a gastight structure which will result in a cost reduction when compared with the suction type which always has to be fully gas tight to avoid ingress of ambient air. A pressure type baghouse is generally constructed as a relatively light steel structure, with either light sheet steel (IBR) or asbestoscement cladding applied to the outside shell, whilst for a suction type unit plate thicknesses of some 4 to 5 $\mathrm{mm}$ and additional reinforcing has to be applied to cope with the negative suction of the system ahead.

As to gasflow through a baghouse we distinguish between the bottom and the top entry system, both being used successfully in many installations throughout the world. Whilst the bottom entry design is one well known to most gascleaning engineers, the top entry system would appear to offer certain advantages in that the gasflow would basically be in a vertically downward direction, assisting thereby the gravity outfall of heavier dust particles into the below situated hoppers, without these particles being attracted to the filter fabric surfaces. Experienced baghouse manufacturers claim that with top entry systems somewhat higher filtration velocities can be tolerated than with the bottom entry design, particularly when generally extremely fine dusts have to be coped with and further, if extreme bag lengths above $10 \mathrm{~m}$ length are being used. 
In bottom entry type baghouse the bags are normally attached to a bottom spigot plate which forms the upper closing plate of the dust hopper. At the top, bags are attached to a bag cap which in turn is springsupported from the baghouse structure. This design enables the bags to be kept under continuous tension and would also facilitate bag replacement. For top entry systems it is necessary to firmly attach the top bag end to a bag thimble similar to the system applied to both designs at the bottom, but for tensioning purposes it is then necessary to make provision for bag take-up through the bag thimble. Incidentally, it has been found that a good glassfibre bag does not need to be taken up more than once after initial plant start-up, a fact which should give relief to engineers who have to look after baghouses which often incorporate more than 1000 bags for one furnace installation. It is, however, essential that bags are tensioned fairly tightly in order to avoid the bags swaying in the baghouse which could have a detrimental effect on bag life.

If glassfibre bags were used, as it would appear to be standard practice in ferro-alloy applications, then it is most important to provide for very gentle treatment during cleaning operations. Generally, the deflation process is being used whereby during the cleaning cycle the individual bag or a whole group of bags is set under slight negative suction, making the bag surfaces to crumble and to break up the accumulated dust layer which would then fall as an agglomerated mass into the below situated hopper system. It is essential to provide for smooth deflation and subsequent re-inflation of the bags, a problem which can only be solved by careful valve design.

Baghouse users have often shown concern about the ability to inspect the interior of a baghouse to check for possible bag failures. Such inspection can be carried out at the lower bag level if sufficient access to individual bags is provided and further if some form of ambient air inducment is provided at this level to enable maintenance personnel to enter the baghouse. If these prerequisites are fulfilled then it is perfectly posible to stay in a baghouse for inspection purposes, even 
if the entry gas temperature was as high as $260^{\circ} \mathrm{C}$.

Another and well justified concern is that of bag replacement in case of need. Here, modern baghouse designs allow isolation of individual groups of filter bags through simple means, enabling maintenance crews to enter these compartments and replace or isolate broken bags at their choice. From investigation it has been found though that most plant operators do not concern themselves unduly if they detect one or several defect bags, since a pinhole in a bag would not affect the overall discharge from the baghouse in a major way. In such instance bag replacements are generally carried out during down periods of the furnace, which would appear to be unavoidable at least from time to time.

The discharge of accumulated ferro-alloy dust from the collecting hoppers of a baghouse sometimes represents problems on account of the previously mentioned low bulk density of the dust. In most instances inverted pyramid type hoppers have proved to be successful but some operators prefer valley type hoppers to provide for easier dust removal from the hopper system. Drag chains have often been used for dust conveying whilst ordinary screw conveyors seem to present difficulties on account of the low dust density. In such instances paddle-type screw conveyors seem to be more reliable.

\section{FINAL DUST DISPOSAL}

Although it would appear feasible to reintroduce ferro-alloy dust into a furnace, it seems that this process is not being used too often. No general statement can be made as to the final use of ferro-alloy dust in operational plants since almost every plant disposes of the dust in a different way. A generally accepted method seems to be to pelletise the dust which is possible by merely adding water to the pelletising process, whilst in other installations sluicing methods are used or the dust is pugged in a suitable device or the dry dust is sold to other concerns for addition to fertilisers or chemicals etc. 


\section{MAIN FANS}

As previously mentioned, the type of fan to be used in a ferro-alloy gas cleaning plant depends mainly on the type of process applied. Where a pressure-type baghouse is installed, the fan must be located on the upstream side of the baghouse and will hence have to deal with almost all the dust exhausted from the furnace. Baghouse plant suppliers in such instance prefer a radially tipped blade design of the fan impeller, to avoid dust to build up on the blades which could result in out-ofbalance conditions of the fan runner assembly.

Although this type of fan does not offer very high efficiencies and thus has a higher power consumption, it is preferred over a backward curved bladed impeller design, on the grounds of the aforesaid. The latter design, however, is fully acceptable for a suction type baghouse, as the dust emission from any type of baghouse is extremely low and hence for this application dust build-ups on the fan blades do not have to be feared.

As to wear on fans used in ferro-alloy applications there have not been too many reports of concern by plant users and it can be generally said that in very few instances only fan impellers or casings were provided with wear liners.

Deflation fans should be designed as paddle type units, as they can at certain times pass excessively large quantities of dust, especially when deflation through the dust hopper system is used. The paddle type fan, although having a low static efficiency, offers best protection against wear which could more easily occur to a different type of fan when used for this application.

\section{PLANT CONTROL}

The prime task in any control system for a gas cleaning plant is to provide for acceptable gas temperatures to the baghouse. Temperature surges as they may occur from time to time must be coped with by the plant. 
Certain plant suppliers use air bleed-in into the duct system ahead of the baghouse, whilst it seems more general to provide for emergency bleed-off in cases of high temperature gas pockets approaching the cleaning installation. Here again, glassfibre filter media offers higher flexibility than other, low temperature fabrics, such as those made from Polyester fibres.

Experience has shown that emergency operations have to be applied reasonably seldom only, as in most instances high temperature gas pockets seem to mix with cooler gases in the system, especially where fairly long duct runs are encountered between furnace and cleaning plant.

As in these installations gas volumes are rather big in most cases and, resultant therefrom fan motor power consumptions are high, it has been found best to control main fans on power consumption, by way of inlet vane control or inlet damper gear. This system is by far cheaper and simpler than to control the fans on speed.

Bag cleaning operations are generally initiated by pressure drop control over the filter installation. It generally takes some 30 to 40 seconds to clean one bag compartment and to bring the pressure drop back to an acceptable level. Obviously, a control system has to be so designed as to provide for full flexibility both in the speed and time used for cleaning individual compartments as well as in the periods applied to change the cleaning cycle from one compartment to the next.

Provided the overall control system for a gas cleaning plant was built to cope with all foreseable conditions, such plant will not need any maintenance and can therefore be operated fully automatically for any length of time. Regular inspection of the plant should, however, be carried out to ensure perfect operating conditions at all times.

\section{CONCLUSION}

It can be firmly stated that sufficient experience is today available by gas cleaning plant manufacturers to design and provide plants which are 
capable of removing harmful ferro-alloy dust from virtually all smelter operations and to achieve clean gas burdens well below $100 \mathrm{mg} / \mathrm{Nm}^{3}$. In fact, most plants produce a gas cleanliness of such high degree that burdens are often less than 50 to $30 \mathrm{mg} / \mathrm{Nm}^{3}$. Although filter bag suppliers are generally reluctant to extend their guarantee for bag life beyond that of general plant, i.e. 12 months, reports received from many parts of the world indicate that life spans for good fabrics, which are applied in the correct way, can extend to 2 years and sometimes even much beyond this period. 